\title{
İkiz Açık Hipotezinin Tarihsel Geçerliliğinin Panel Veri Yaklaşımı ile Analizi
}

\author{
DOI: 10.26466/opus.698699
}

*

\author{
Mehmet Çetin * \\ *Dr. Öğr. Üyesi, Dokuz Eylül Üniversitesi \\ E-Posta: $\underline{\text { mehmet.cetin@deu.edu.tr } \quad \text { ORCID: } 0000-0002-6954-0908}$

\section{Öz}

Bütçe açığı ve dış ticaret açığı politika yapıcılar için ekonominin iç ve dış dengesini yansıtan iki önemli göstergedir. Bu iki göstergede eş anl olarak yaşanabilecek dengesizlikler makroekonomik olumsuzlukların bir işaretidir. 1970'li yılların sonlarında hem gelişmiş ve hem gelişmekte olan ekonomiler, eş zamanl dış ticaret ve bütçe açı̆̆ı sorunsalı ile karşı karşıya kalmışlardır. Bu iki açı̆̆ın birbirini etkilediği varsayımından hareket eden İkiz Açık Hipotezi, esasen 1980'li yıllarda ABD ekonomisinde meydana gelen dengesizlikleri açıklamaya çalışmaktadır. 1980'li yılların ilerleyen dönemlerinde birçok iktisatçı bu hipotezi geliştirmeye yönelik yeni savlar ortaya atmış; kamu dengesi ve dış dengeyi ilişkilendiren farklı mekanizmalar ileri sürmüşlerdir. Bu çalışmanın amacı İkiz Açık Hipotezi'nin 19. yüzyılın sonlarında başlayan ve I. Dünya Savaşı'na kadar aralıklı bir biçimde devam eden küresel depresyon ve savaş öncesi istikrarsızlık ortamında geçerli olup olmadığının test edilmesidir. Bunun için 1881-1913 döneminde 46 ülke için farklı ülke grupları altında panel veri yaklaşımı ile İkiz Açık Hipotezi test edilmiştir. Elde edilen bulgular, İkiz Açık Hipotezi'ne iliş̧in geleneksel yaklaşımın reddi yönündedir. Nedensellik test sonuçları ise dış dengeden iç dengeye doğru tek yönlü bir nedensellik ilişkisinin varlığını göstermektedir

Anahtar Kelimeler: İkiz Açık Hipotezi, Panel Veri Analizi, Tarihsel Yaklaşım 


\title{
The Analysis of the Historical Validity of the Twin Deficit Hypothesis with Panel Data Approach
}

\begin{abstract}
The budget deficit and the foreign trade deficit are two important indicators for policy makers that reflect the internal and external balance of the economy. The imbalances that may occur simultaneously in these indicators are a sign of macroeconomic problems. Both developed and developing economies faced the problem of simultaneous foreign trade and budget deficits in the late 1970s. Based on the assumption that these two variables affect each other, the Twin Deficit Hypothesis mainly tries to explain the imbalances in the US economy in the 1980s. Later in the 1980s, many economists developed new arguments for this hypotheses and proposed different mechanisms linking the internal and the external balances. The aim of this study is to test whether the Twin Deficit Hypothesis is valid or not in the global depression and the political instability that started in the late 19th century and continued intermittently until the First World War. For this, the twin deficit hypothesis was tested for 46 countries in the 1881-1913 period under different country groups with a panel data approach. The findings are in the rejection of the traditional approach to the twin deficist hypothesis. The causality test results show the existence of a one-way causality relationship from the external balance to the inner balance.
\end{abstract}

Keywords: Twin Deficit Hypothesis, Panel Data Analysis, Historical Approach 


\section{Giriş}

Kamu harcamalarında meydana gelen artş nedeniyle ortaya çıkan bütçe açığının diş denge üzerinde ortaya çıkardığı olumsuz etki, literatürde ikiz açık olarak adlandırılmaktadır (Parkin, 2000, s.848). Amerikan ekonomisinde 1980'li yıllarda meydana gelen gelişmeler üzerine ortaya atılan hipotezi açılamaya yönelik farklı teorik yaklaşımlar geliştirilmiştir. Bu yaklaşımlardan Tanzi (1982) tarafından geliştirilen yaklaşıma göre mali dengesizliklerin ortaya çıkmasında, kamu harcamalarındaki artışlar, dış ticaret hadleri ve ihracattaki değişmeler önemli birer etkendir (Tanzi, 1982, s.1069). Cari işlemler açığının ortaya çıkması, özel tasarruflarda ortaya çıkan azalmanın veya kamu açıklarında ortaya çıkan yükselişin belirtisi olarak değerlendirilebilir. Bu anlamda açık ekonomi koşullarında kamu veya diğer bir ifadeyle bütçe açıkları, ülkenin dış ekonomik dengesini etkileyen faktörler arasında yer almaktadır (Kenen, 2000, s.286; Krugman ve Obstfeld, 2014, s.371-372).

Genel denge modeli kapsamında yurt içi tasarruflar, yatırımlar ile dış kaynak toplamına eşit olduğundan, kamu açıkları yurt içi tasarrufları azalttığında yatırımlar ve dış kaynak girişi azalmak durumundadır. Bu durumda kamu açıkları, cari işlemler açığının artmasına neden olabilmektedir. Öte yandan iktisat literatüründe ikiz açılara yönelik geleneksel açılamaya göre kamu açıkları yine faiz kanalı üzerinden ve sermaye girişi vasıtasıyla yerli parayı değerlendirerek; dış ticaret açığını büyütebilmektedir (Ball ve Mankiw, 1995, s.3-5; Feldstein, 1986, s.7). Bu mekanizma, maliye politikaları ile cari işlemler dengesi arasındaki ilişkiyi açılayan ve Neoklasik ve Keynesyen görüşlerin bir sentezi olan Mundell-Fleming Modeli ile de tutarlıdır. Nitekim Geleneksel Keynesyen yaklaşım, cari işlemler açığı ile bütçe açıkları arasındaki güçlü kolerasyonun varlı̆̆ını, Mundell-Fleming Modeli ve Keynesyen gelir-harcama yaklaşımı ile temellendirmektedir (Dibooğlu, 1994, s.3-4).

Obstfeld ve Rogoff (1996), gelirin nesiller arasında yeniden tahsis edildiği, Örtüşen Nesiller Modeli'nde bütçe açıklarının cari açığa neden olabileceğini ifade etmekte ve bu duruma ABD'nin 1980'li yıllarda yaşadığı ikiz açık sorunsalının örnek gösterilebileceğini belirtmektedir. Barro (1989)'a göre ise standart bir analizde bir ülkenin açık bütçe politikası daha yüksek faiz oranlarından ziyade dış borçlanmayı tetikleyecek ve böylelikle cari açık ortaya çıkacaktır. Faiz oranlarındaki artışın cari açı̆̆ı etkileyebilmesi için söz konusu artışın küresel piyasalara etki edebilecek boyutta olması yahut artan ulusal 
borçların yabancı alacaklıları daha yüksek getiri beklentisine sokması gerekmektedir. Ricardian Eşdeğerlilik Kuramı'na göre ise kapalı ekonomilerde bütçe açıklarına bağlı olarak kamu tasarruflarında meydana gelen azalma, özel tasarruflardaki artışla dengeleneceğinden yurt içi tasarruflarda, toplam tasarruf ve toplam yatırım talebini eşitlemek için reel faiz oranının yükselmesini gerekli kılacak herhangi bir değişme meydana getirmez. Açık ekonomilerde ise planlanan tasarruflar, dış borçlanmaya yönelik gerekliliği ortadan kaldıracak ölçüde artacağı için kamu açıklarının cari denge üzerinde herhangi bir etkisi olmayacaktır. Böylece bütçe açı̆̆ı da cari açı̆̆ın bir nedeni olmayacaktır (Barro, 1989, s.4). Kim ve Roubini (2008), genişletici mali şokun reel döviz kurunda değer kaybına yol açarak; cari işlemler dengesini olumlu yönde etkileyeceğini ifade etmiş ve ikiz ayrışma (ikiz sapma) kavramını ileri sürmüştür. Bu anlamda kamu harcamalardaki artış, cari dengeyi İkiz Açık Hipotezi'nin tersine iyileştirebilmektedir. Buna göre hükümet bütçesindeki ve ticaret dengesindeki içsel hareketler, İkiz Açık Hipotezi'ni geçersiz kılmaktadır. Ekonominin daraldığı dönemlerde çıktı azalmakta ve bütçe dengesi ekonomik durgunluk nedeniyle bozulmaktadır. Çıktıdaki azalma ise yatırımdaki ve yurt içi tasarruftaki azalmadan daha derin bir azalmaya yol açtığından ticaret dengesi iyileşebilmektedir.

Utkulu (2003)'e göre Klasik, Keynesyen ve Parasalcı iktisat okullarının İkiz Açık Hipotezi'ne ilişkin yaklaşım farklılıkları, farklı makroekonomik araçların ödemeler dengesi üzerinde düzenleyici bir etkiye sahip olacağı düşüncesinden kaynaklanmaktadır. Bu anlamda Parasalcı yaklaşım para arzı aracını vurgularken, Keynesyen yaklaşım daraltıcı maliye politikasına ve Klasik Okul ise döviz kurlarına vurgu yapmaktadır.

Bu çalışmada İkiz Açık Hipotezi, tarihsel veriler üzerinden ele alınmaktadır. Bu bağlamda ekonometrik analize dâhil edilen ülkeler; merkez ülkeler ve Pamuk (2005)'in ülkelerin içyapıları ve bu yapıların kapitalist sistem ile olan etkileşimi bağlamında yaptığı tasnife uygun şekilde çevre ülkeler şeklinde gruplandırılmıştır. Pamuk (2005), çevre ülkelerini; resmi sömürgeler, gayri resmi imparatorluk kümesinde yer alan ülkeler ve Osmanlı Devleti'nin de içinde yer aldığı siyasi anlamdaki bağımsızlığını emperyal politikalar takip eden devletler arasındaki rekabet şartlarında devam ettiren ülkeler olarak üç farklı kümede kategorize etmektedir. Resmi sömürgelerin en temel niteliği, kapitalist sistem ile entegrasyon sürecinin merkezi gücün tam denetiminde 
gerçekleşmiş olması, çevre ülkesinin dış ticaret politikasından takip ettiği iktisadi politikalara ve hatta tarım sektöründeki üretim yapılarına kadar pek çok alanın merkez ülke tarafından düzenlenmiş olmasıdır. Çevre ülkesi olarak resmi sömürge, merkez ülkeye tarım ürünleri satan ve ondan mamul mallar alan bir ekonomi haline getirilmektedir. Ayrıca merkez ülkenin sömürgesinde kurduğu idare, sömürge yönetiminin masraflarının karşılanması amacıyla bir dizi vergi koymakta ve hatta çevre ülkeyi borçlandırmaktadır. Gayri resmi imparatorluk kümesine dâhil olan çevre ülkeler ise siyasal bağımsızlıklarını sürdürmekle birlikte tek bir merkez ülkenin etki alanındadır. Bu ülkelerde merkezdeki sermayedarlar ile çevredeki büyük toprak sahipleri ve tüccar kesiminin çıkar birliği söz konusudur. Orta ve Güney Amerika ülkeleri bu grubun en temel örnekleridir. Osmanlı İmparatorluğu'nun da içerisinde yer aldığı son kümede ise bürokrasinin gücünü nispeten koruyor olması nedeniyle kapitalizme açılış süreci ancak merkez ile bürokrasi arasındaki pazarlıklar, baskılar ve uzlaşma yoluyla gerçekleşmektedir.

Nihayetinde merkez ülkenin temel amacı çevre ülkesindeki üretim kalıplarını kendi çıkarları doğrultusunda yönetmek ve yönlendirmektir. Bu süreç, çevre ülke için hem potansiyel bir dış ticaret açığı hem de potansiyel bir bütçe açı̆̆ını içerisinde barındırmaktadır. Üstelik çalışmanın dönem aralığı olan 1881-1913 dönemi aynı zamanda tekelci kapitalizmin emperyalizme evrildiği dönemdir. Emperyalizm teorisi, sömürgecilik faaliyetlerini ve bu bağlamda merkez-çevre ilişkilerini, kapitalist merkez ülkelerinin ekonomik ihtiyaçları üzerinden açıklamaktadır. Buna göre merkez ülkelerde ekonomiye egemen duruma gelen ve ellerinde önemli ölçüde mal ve sermaye biriktiren büyük ölçekli işletmelerin ellerindeki sermayeyi daha kârlı yatırım alanlarına yönlendirme ihtiyacı, emperyalist politikaların motive edici gücü olmuştur (Güran, 2017, s.110).

Emperyalizmin en önemli aracı, sermaye ihracıdır. Sermaye ihracının önemli bir bölümü merkez ülkeler tarafından çevre ülkelerine verilen borçlardan meydana gelmektedir. Sermaye ihracı yoluyla yaratılan diş borçlar, merkez ülkelerin çevre ülkelerin gümrük ve ticaret politikaları üzerinde mali denetim kurmalarına imkân veren güvenilir bir araçtır. Çevre ülkeleri borçlanmaya iten neden ise harcamalarının mal ithalatının gerektirmesi, bu gereksinimin çevre ülkesinin ödemeler dengesinde açıklara yol açması ve yurtiçi kaynakların kamu harcamalarını karşılayamamasıdır (Çetin ve Kök, 2015, s.208). 
Bu çalışmada 1881-1913 dönem aralığı ve 46 ülke için İkiz Açı Hipotezi'nin geçerliliği analiz edilmektedir. Söz konusu 46 ülke Pamuk (2005)'in tasnifine büyük ölçüde uyarak üç farklı grupta; merkez ülkeler, çevre ülkeler; gayri resmi imparatorluk kümesi ve resmi sömürgeler olarak ele alınmaktadır. Dönemin avam kamarası kayıtlarında ve ülke yıllıklarında Osmanlı Devleti, merkeze bağlı ve yıllık olarak vergi ödeyen eyaletlere sahip bir imparatorluk olarak değerlendirildiğinden ve hiçbir zaman resmi bir sömürge olmadığından merkez ülkeler içerisinde değerlendirilmiştir. Bu anlamda farklı gruplar için yapılacak ekonometrik analizlerde elde edilecek bulgu farklılıkları, müteakip çalışmalar için bir motivasyon sağlayacaktır. İkiz Açık Hipotezi'nin nispeten güncel bir teori olması, bu hipotezin tarihsel geçerliliğinin sorgulanmasının ihmal edilmesine neden olmuştur. Bu anlamda literatürde çok az çalışma bulunmaktadır. Bu durum bu çalışmanın da hem önemini hem de başlangıç noktasını oluşturmaktadır. Çalışmanın takip eden bölümünde öncelikle literatür taraması yer almaktadır. Literatür taramasından sonra farklı ülke kategorileri için İkiz Açık Hipotezi'nin geçerliliği ekonometrik analiz araçları ile test edilmektedir. Son bölümde ise ekonometrik bulgular doğrultusunda sonuç kısmına yer verilmektedir.

\section{Literatür Taraması}

İkiz açık hipotezine ilişkin tartışmalar 1970'li yıllarda ABD'de başlamış ve iki değişkenin 1980'li yıllarda Reagan döneminde eş anlı bir biçimde açık vermesi, bir ikiz açık sorunsalının varlığını gündeme getirmiştir. İlk çalışmalarda temel olarak dış ticaret açı̆̆ı ile bütçe açı̆̆ı arasındaki ilişki analiz edilmiş; 1990'lı yıllarla birlikte sermaye hareketleri serbestisinin ardından çalışmalar derinlik kazanmıştır (Günaydın, 2004, s.149). Genel olarak bakıldığında ülke grupları yahut tekil ülke incelemelerinde ve farklı yöntemler altında İkiz Açık Hipotezi'nin geçerliliğine ilişkin ortak bir görüş birliğine varılamamıştır. Literatürdeki çalışmaların büyük kısmı ABD ekonomisine yoğunlaşmıştır.

Öncü çalışmalardan biri olan Evans (1988), 1947-1985 dönemi çeyrekli ABD verilerini kullanarak; Ricardian Denklik Hipotezi'ne karşı Blanchard'ın alternatif modelini test etmiş; Blanchard Modeli'ni destekleyen herhangi bir bulgu ile karşılaşmamış, böylece cari açık ile kamu açığı arasında hiçbir ilişkinin olmadığı sonucuna ulaşılmıştır. 
Abell (1990), VAR modeli ile 1979 - 1985 dönemi ABD ekonomisi için kamu açığı ile dış ticaret açığı arasındaki bağlantıyı test etmiş ve bütçe açılarından, yüksek faiz oranları, yabancı sermaye akımı, döviz kurları ve nihayetinde diş ticaret açıklarına doğru dolaylı bir ilişkinin varlığını ortaya koymuştur. Buna göre bütçe açığı dış ticaret açığının doğrudan sebebi değilken, dış ticaret açı̆̆ı bütçe açığının doğrudan nedenidir.

Dewald ve Ulan (1990), 1954-1987 ABD ekonomisinde reel olarak bütçe dengesi ve cari işlem dengesi arasındaki ilişkiyi nedensellik testi ile test etmişlerdir. Yazarlar söz konusu ilişkinin teorik olarak var olabilmesi için bütçe açığının reel faiz oranlarını sermaye akışına yol açabilecek ölçüde etkilemesi gerektiğini vurgulamaktadır. Bununla birlikte çalışmanın bulguları cari işlemler dengesi ile bütçe dengesi arasında her iki verinin de enflasyondan arındırılmış ve nominal değerler üzerinden ifade edilmeleri durumunda sistematik bir ilişkinin söz konusu olmadığ yönündedir.

Biswas, Tribedy ve Saunders (1992), 1950-1988 döneminde ABD ekonomisinde federal bütçe açıkları ile net ihracat arasındaki bağlantıları, enflasyondan arındırılmış verilerle ve reel değerler arasındaki nedensellik ilişkisi bağlamında analiz etmektedir. Çalışmada yapısal ve fiili bütçe açıkları arasında bir ayrıma gidilmiş ve Hsiao (1979 ve 1981) yardımı ile minimum tahmin hatası sağlayacak bir gecikme uzunluğu elde edilmiştir. Çalışmanın bulguları yapısal bütçe açıklarından net ihracata doğru ve tek yönlü bir nedensellik bağlantısının var olduğunu göstermektedir.

Kim ve Roubini (2008), 1973-2004 dönemi çeyrekli veriler ile ABD ekonomisinde cari denge ve bütçe dengesi arasındaki bağlantıyı Vektör Otoregresyon yöntemi ile analiz etmiştir. Çalışmada elde edilen bulgulara göre geleneksel görüşün aksine bütçe açığının cari dengeyi iyileştirdiği bunun da artan bütçe açıklarının reel döviz kurunu düşürmesi nedeniyle olduğu sonucuna ulaşılmıştır. Bu anlamda cari açık ile bütçe açığı arasında ikiz açıktan ziyade ikiz sapma ilişkisi söz konusudur.

Ülke grupları için İkiz Açık Hipotezi'ni test eden çalışmalara baktığımızda ise Berheim (1988), birbirlerinin önemli ticaret ortakları olan ABD, Kanada, İngiltere, Almanya, Japonya ve Meksika için dış ticaret ve bütçe açığı arasındaki ilişkiyi 1960-1984 dönemi için doğrusal regresyon analizi ile test etmiştir. Ülkeler arasında söz konusu değişkenlerin etki derecesi değişmekle ve Japonya için nispeten zayıf olmakla birlikte bütçe açığındaki artışlar, bütün ülkeler için cari açıkta bir artışa neden olmaktadır. 
Kasa (1994), ABD, Japonya ve Almanya ekonomileri için ve farklı tarih aralıklarında Vektör Otoregresyon yöntemini kullanarak İkiz Açık Hipotezi'ni test etmiştir. Çalışmanın bulguları kısıtsız VAR tahmini için her üç ekonomide bütçe dengesinden cari dengeye doğru bir nedensellik ilişkisini ortaya koymakta iken; kısıtlı VAR tahmini için sadece ABD ekonomisinde bütçe dengesinden cari dengeye doğru bir nedensellik ilişkisini ortaya koymuş; Japonya ve Almanya için herhangi bir nedensellik söz konusu olmamıştir.

Bilgili ve Bilgili (1998), Türkiye, Singapur ve ABD ekonomileri için İkiz Açık Hipotezi'ni dış açık, milli gelir, döviz kuru, bütçe açı̆̆ı, faiz oranları ve para arzı değişkenlerini dahil ederek OLS yöntemi ile tahmin etmiş ve analiz neticesinde kamu ve cari açık değişkenleri arasında herhangi bir ilişkinin varlığına ulaşamamıştır.

Anoruo ve Ramchander (1998), Kore, Filipinler, Hindistan, Endonezya ve Malezya için kamu dengesi ve cari denge arasındaki bağlantıyı 1975-1996 döneminde Granger Nedensellik Testi vasıtasıyla analiz etmiştir. Çalışmanın bulgularına göre cari işlemler dengesinden kamu dengesine doğru ve tek yönlü nedensellik ilişkisi söz konusudur.

Piersanti (2000), OECD ülkelerinde bütçe açı̆̆ı ile cari açık arasındaki bağlantıyı 1970-1997 dönemi için Nedensellik testi vasıtasıyla test etmiştir. Çalışmanın bulgularına göre bütçe açıkları, dış ticaret açıklarını arttırmakta olup İkiz Açık Hipotezi ampirik olarak geçerlidir.

Kulkarni ve Erickson (2001), Hindistan, Pakistan ve Meksika ekonomileri için bütçe dengesi ile cari denge arasındaki bağlantıyı 1969-1997 döneminde Granger Nedensellik Testi vasıtasıyla test etmiş ve çift taraflı ve karşılıklı etkilerin mevcut olduğu sonucuna ulaşmıştır.

Salvatore (2006), 1973-2005 dönemi için G-7 ülkelerinde İkiz Açık Hipotezi'nin geçerliliğini regresyon yöntemi ile analiz etmiştir. Analiz neticesinde bütçe açı̆̆ının gecikmeli değerleri ile cari işlemler dengesinin cari değerleri arasında pozitif yönlü bir ilişkinin varlığına ulaşılmıştır. Lau ve Baharumshah (2006), ikiz açık hipotezini 1980-2001 dönemi yıllık verileriyle ve panel veri analizi yöntemiyle SEACEN ülkeleri için analiz etmektedir. Çalışmanın bulguları bütçe açı̆̆ının cari işlemler açığını doğrudan ve dolaylı olarak etkilediği yönündedir. Buna göre iki değişken arasındaki nedensel ilişki; biri bütçe açı̆̆ı ile cari açık arasında doğrudan ve diğeri de döviz kurları ve faiz oranları vasıtasıyla dolaylı olarak gerçekleşmektedir. 
Beetsma vd. (2008), 1970-2004 döneminde bütçe dengesi ve cari denge arasındaki bağlantıyı 14 Avrupa Birliği ülkesi için Panel VAR yöntemini kullanarak yıllık verilerle analiz etmiştir. Çalışmada kamu harcamalarında meydana gelecek bir artışın ticaret dengesi ve bütçe açıları üzerinde yaratacağı sonuçlar değerlendirilmektedir. Bu anlamda Keynesyen kamu harcamaları çarpanının varlığı üzerinden hareket edilmiştir. Çalışmanın bulguları İkiz Açık Hipotezi'nin geçerliliğini doğrulamaktadır.

Literatürde hipotezin Türkiye ekonomisi için geçerliliğini test eden çok sayıda çalışma da bulunmaktadır. Eroğlu (1998), 1984-1994 döneminde çeyrekli verilerle Türkiye ekonomisi için kamu dengesi ile cari denge arasındaki bă̆lantıyı Nedensellik ve Eşbütünleşme testleri ile analiz etmiştir. Çalışma özellikle sermaye hareketlerinin serbestleştirilmesi neticesinde makroekonomik göstergelerde meydana gelen bozulmalara dikkat çekmektedir. Çalışmanın bulguları, ikiz açık hipotezinin geçerliliğini; kamu kesimi açıklarının cari işlemler açıklarını etkilediğini göstermektedir.

Utkulu (2004), Türkiye ekonomisinde cari denge ile bütçe dengesi bağlantısını Keynesyen Yaklaşımı ve Ricardian Denklik Hipotezi'ni ampirik olarak test ederek araştırmaktadır. Koentegrasyon analizi vasıtasıyla nedensellik analizi yapılan çalışmanın bulguları, Keynesyen İkiz Açık Hipotezi'ni desteklemekte, dış açık ile bütçe açığının uzun vadede beraber hareket ettiğini ortaya koymaktadır.

Aksu ve Beşer (2005), 1989-2003 dönemi aylık verilerle diş açı ile bütçe açığı arasındaki bağlantıyı Türkiye ekonomisi için analiz etmişlerdir. Çalışmada bütçe giderlerinin bütçe gelirlerine ve ithalatın ise ihracata oranı kullanılarak VAR analizi yapılmıştır. Çalışmanın bulgularına göre bütçe açığı dış ticaret açı̆̆ını etkilemekte iken dış açı̆̆ın bütçe açı̆̆ı üzerindeki etkisi ise gecikmeli bir biçimde kendisini göstermektedir.

Erdinç (2008), İkiz Açıklar Hipotezi'nin geçerliliğini 1950-2005 dönemi Türkiye ekonomisi için koentegrasyon analizi ve nedensellik testi vasıtasıla test etmektedir. Ekonometrik analiz neticesinde çalışmanın bulgularına göre cari açık ile bütçe açığı arasında uzun vadeli bir bağlantının olduğu sonucu elde edilmiştir. Böylece sonuç olarak Geleneksel Keynesyen Yaklaşım desteklenmektedir. Nedensellik analizi cari açık ve bütçe açığı arasındaki bağlantının yönünün bütçe dengesinden cari dengeye doğru olduğunu göstermektedir. 
Turan ve Karakaş (2017), 1998-2016 dönemi için çeyrekli veriler ile Türkiye ekonomisinde merkezi yönetimin bütçe dengesi ile cari işlemler arasındaki dengeyi NARDL (Doğrusal olmayan sınır testi) yaklaşımı ile analiz etmişlerdir. Çalışmanın bulgularına göre cari işlemler dengesindeki olumlu yahut olumsuz şoklar uzun dönemde bütçe üzerinde anlamlı etkiler yaratmakla birlikte değişkenler arasında eşbütünleşme ilişkisi söz konusu değildir. Bu doğrultuda ilgili dönem aralığında Türkiye ekonomisinde İkiz Açık Hipotezi desteklenememektedir.

Kılavuz ve Dumrul (2012), Türkiye ekonomisinde cari açık ile kamu açığı arasındaki bağlantıyı 2006 - 2010 yılları ve aylık verilerle VAR yöntemi, Sınır testi ve Granger nedensellik testi yardımı ile analiz etmişler ve Ricardocu yaklaşımla uyumlu bir şekilde iki değişken arasında uzun vadede herhangi bir ilişkinin var olmadığı sonucunu bulmuşlardır.

Tekil olarak farklı ülkeleri ele alan çalışmalarda ise Evans ve Hassan (1994), Kanada ekonomisi için 1960-1988 dönemini kapsayan analizlerinde Ricardian Denklik Hipotezi'ni reddedememişler; Kaufman, Scharler ve Winckler (1999), Avusturya ekonomisi için 1976-98 döneminde İkiz Açık Hipotezi'nin reddine ve Mammadov (2008), Azerbaycan ekonomisinde 19922006 dönemi çeyrekli verilerle yaptığı nedensellik testi neticesinde cari denge ile bütçe dengesi arasında nedensellik bağının bulunmadığı sonucuna ulaşmışlardır.

Alkswani (2001), Suudi Arabistan ekonomisi için 1970-1999 dönemi verileriyle cari açığın bütçe açığını etkilediğine, Vamvoukas (1999), Yunanistan ekonomisi için 1948-94 dönemi için yıllık veriler ile cari denge ile bütçe dengesi arasında kısa ve uzun vadede anlamlı bir bağın bulunduğu ve Vyshnak (2000), 1995-1999 dönemi çeyrekli veriler ile İkiz Açık Hipotezi'nin Ukrayna ekonomisi için geçerli olduğu sonucuna ulaşmıştır.

Literatürde yer alan az sayıdaki tarihsel çalışmalardan Bilman (2019), 1846-1912 dönemi Osmanlı ekonomisi için İkiz Açı Hipotezi'nin varlığını Granger ve Fourier Granger nedensellik analizlerinin yardımıyla test etmiş ve Ricardo denkliği hipotezinin geçerli olduğu bulgusuna ulaşmıştır. Çalışmada veri seti olarak Aksu ve Beşer (2005)' in aksine bütçe gelirlerinin bütçe giderlerine ve ihracatın ise ithalata oranı kullanılmıştır. 


\section{Ekonometrik Uygulama}

Çalışmada B. R. Mitchell (1982 ve 1998), The Statesman's Year-Book, Güran (2003) ve Pamuk (1995)'ten elde edilen veriler kullanılarak 46 ülke* için 18811913 yılları arasında İkiz Açık Hipotezi'nin geçerliliği test edilmiştir. Bütçe dengesi (LRX), bütçe gelirlerinin bütçe harcamalarına ve dış ticaret dengesi (LXM) ise ihracatın ithalata oranı olup logaritmik olarak tanımlanmış; böylece ülkelerin kullandıkları para birimlerinin birbirlerine dönüştürülmesinde, ülkelerin siyasi yapılanmalarında ve 1905 yılında Avusturya - Macaristan Devleti'nin hesap birimi olarak Gulden'den Kronen'e geçmesi örneğinde olduğu gibi hesap biriminde meydana gelen değişmelerden kaynaklanabilecek sıkıntıların önüne geçilmiştir. Söz konusu 46 ülke; merkez ülkeler ve çevre ülkeler kategorisinde yer almakla birlikte çalışmanın dönem aralığında hali hazırda sömürge statüsünde olan ülkeler (resmi sömürgeler) ve geçmişinde uzun süre resmi bir sömürge olarak varlı̆̆ını sürdürmüş, 19. yüzyılın ilk çeyreğinde bağımsızlığını kazanmış olmakla birlikte Pamuk(2005)'in tasnifine göre herhangi bir merkez ülkenin gayri resmi imparatorluğuna dâhil olan ülkeler (gayri resmi imparatorluklar) olmak üzere üç farklı kategoride ele alınmıştır. Bu bağlamda üç farklı ülke grubu ve bütün ülkeleri içerisinde alan genel bir analiz ile birlikte ekonometrik analizler toplamda dört farklı kategori için yapılmıştır. Model tahminlemesinde Eviews 9, Gauss ve Gretl programlarından faydalanılmıştır. Model tahminlemesinin yapılmasından önce değişkenlerin durağanlık derecesinin belirlenmesi amacıyla birim kök testleri yapılmıştır.

\section{Panel Birim Kök Testleri}

19. yüzyıl ilk küreselleşme çağı olarak nitelendirildiğinden ve bu dönemde her ne kadar günümüzle karşılaştırıldığında ulaştırma ve haberleşme olanaklarının daha kısıtlı olduğunu kabul etsek de telgraf, telefon, okyanus ve demiryolu taşımacılığının göstermiş olduğu ilerleme dikkate alındığında uluslararası ekonomik ilişkiler büyük bir gelişme göstermiştir. Karşılıklı iktisadi

\footnotetext{
* Merkez Ülkeler: ABD, Almanya, Avusturya-Macaristan, Birleşik Krallık, Belçika, Danimarka, Hollanda, Fransa, ispanya, isviçre, Isveç, italya, Norveç, Japonya, Osmanlı Devleti, Portekiz, Rusya; Gayrı resmi Imparatorluklar: Arjantin, Brezilya, Bulgaristan, El Salvador, Guatemala, Kosta Rika, Meksika, Romanya, Şili, Venezuela; Resmi Sömürgeler: Avustralya, Barbados, Boğaz Yerleşimleri (bugünkü Singapur, Malacca, Penang ve Dinging), Cezayir, Endonezya, Fiji, Gana, Güney Afrika, Hindistan, Ingiliz Guyanası, Jamaika, Kanada, Morityus (Mauritius), Mısır, Nijerya, Sierra Leone, Sri Lanka (Seylan), Trinidad, Yeni Zelanda.
} 
ilişkilerin gösterdiği gelişme, ülkeler arasındaki karşılıklı etkileşimi attırmaktadır. Buna bağlı olarak ekonometrik analiz safhasında yatay kesiti oluşturan bu birimler arasında da karşılıklı etkileşimler söz konusu olmaktadır. Bu durum yatay kesit bağımlılığı olarak adlandırılmaktadır. Birinci nesil birim kök testleri, yatay kesit bağımlığının olmadığı varsayımı ile geliştirilmişken; ikinci nesil birim kök sınamaları ise yatay-kesit bağımlılı̆̆ının var olduğu varsayımı ile işlemektedir (Breusch ve Pagan, 1980). Buna bağlı olarak birim kökün var olup olmadığını sınamak için ilk olarak yatay kesit bağımlılığının araştırılması gerekmektedir. Birinci nesil panel durağanlık testlerinde seriyi oluşturan yatay kesitler arasında herhangi bir bağımlılık yoktur ve seriyi meydana getiren birimlerden herhangi birinde ortaya çıkabilecek bir şoktan tüm birimlerin eş düzeyde etkilendiği varsayımı yapılmaktadır. İkinci nesil panel birim kök testlerinde ise paneli meydana getiren birimlerde ortaya çıkacak bir şokun tüm birimlerde farklı ölçüde etkiler yaratacağı varsayılmaktadır (Yalçınkaya ve Kaya, 2017, s.5).

Phillips ve Sul (2003)'e göre yatay kesit bağımlılı̆̆ı etkin olmayan tahminlere yani analiz sonuçlarında önemli sapmalara yol açmaktadır. Çalışmada kullanılacak birim kök testleri, yatay kesit bağımlığının test edilmesi neticesinde elde edilecek sonuçlara göre belirlenecektir (Pesaran, 2004). Yatay kesit bağımlılığının olması durumunda ikinci nesil, olmaması durumunda ise birinci nesil birim kök testleri kullanılmaktadır (Tatoğlu, 2017, s.2-21).

Bu çalışmada ülkeler farklı gruplar halinde analiz edileceği için ülkelerin tümünün dâhil edildiği analiz için birim boyutu (46 ülke) zaman boyutundan (33 yıl) büyük olduğu için Pesaran (2004) yatay kesit bağımlılı̆̆ı testi, merkez, çevre (resmi sömürgeler) ve yarı-çevre (gayri resmi imparatorluk grubu) ülkeler için ise birim boyutu zaman boyundan küçük olduğu için Breusch ve Pagan (1980) tarafından geliştirilen LM testi kullanılmıştır.

\section{Tablo 1. Yatay Kesit Bağımulı̆̆ı Test Sonuçları}

\begin{tabular}{lll}
\hline \multirow{2}{*}{ Model } & Test Sonuçları & \\
\cline { 2 - 3 } Tüm Ülkeler (Model 1) & Pesaran (2004) & LM Testi \\
Merkez Ülkeler (Model 2) & $-1,776566(0.0756)$ & - \\
Gayrıresmi İmparatorluk (Model 3) & - & $4634.444(0.0000)$ \\
Resmi Sömürgeler (Model 4) & - & $657.8482(0.0000)$ \\
\hline
\end{tabular}

Not: Tablodaki değerler Eviews 9 programı kullanılarak yazar tarafından hesaplanmıştır. 
Yatay kesit bağımlılığı testinden elde edilen sonuçlara göre tüm ülkelerin yer aldığı birinci modelde elde edilen olasılık değeri \%5'ten büyük olup yatay kesit bağımlılığı yoktur. Bununla birlikte merkez ülkeler, resmi sömürgeler ve yarı çevre (gayri resmi imparatorluk grubu) için ayrı ayrı yapılan testlerde elde edilen olasılık değerleri \%5'ten küçük olduğundan yatay kesit bağıml-lığının var olduğu görülmektedir. Dolayısıyla birimler arası korelasyon söz konusudur. Bu çerçevede bir sonraki adımda birinci model için birinci nesil birim kök testleri, diğer modeller için ise ikinci nesil testler uygulanacaktır.

Klasik regresyon modelleri ile yapılan tahminler, bağımlı ve bağımsız değişken serilerinin durağan olduğu varsayımına dayanmaktadır. Zaman serisi analizi çerçevesinde yapılan çalışmalarda kullanılan serilerin durağan olmaması yani birim kök içermesi halinde regresyon sonuçları değişkenler arasındaki gerçek ilişkiyi yansıtmamakta ve dolayısıyla elde edilen regresyon modeli sahte olabilmektedir (Granger ve Newbold, 1974, s.119). Bu nedenle panel veri analizi yapmadan önce veri setinin durağanlık durumu test edilmelidir. Çalışmada Model 1 için yatay kesit bağımlılığı testinin sonuçları ile tutarlı bir biçimde birinci nesil birim kök testlerinden; ADF-Fisher testi, Levin, Lin ve Chu(2002), Im, Pesaran ve Shin (2003) ve PP-Fisher testi uygulanmıştır. Birinci nesil testler yatay kesit bağımlılı̆̆ını ölçmeyi hedefleyen fakat yatay kesit verilerinde şok etkisi meydana getirebilecek değişmelerin tüm yatay kesitler için aynı etkiyi yapacağını kabul eden testlerdir (Yıldırım vd., 2013, s.88). Bu bağlamda gerçekleştirilen birim kök testlerinden elde edilen sonuçlar aşağıdaki gibidir.

Tablo 2. Model 1 Panel Birim Kök Test Sonuçları

\begin{tabular}{lllllllll}
\hline Model 1 & \multicolumn{2}{l}{ Levin, Lin ve Chu } & \multicolumn{2}{l}{ Im Pesaran ve Shin } & \multicolumn{2}{l}{ ADF-Fisher } & \multicolumn{2}{l}{ PP-Fisher } \\
Değişkenler & İst. de- & Olasılık & İst. de- & Olasılık & İst. de- & Olasllk & İst. de- & Olasılık \\
& ğeri & değeri & ğeri & değeri & ğeri & değeri & ğeri & değeri \\
LXM & -3.7912 & 0.0001 & $-5,2282$ & 0.0000 & 179.292 & 0.0000 & 258.971 & 0.0000 \\
LXR & -8.1379 & 0.0000 & -9.6746 & 0.0000 & 264.412 & 0.0000 & 418.984 & 0.0000 \\
\hline
\end{tabular}

Not: Tablodaki değerler Eviews 9 programı kullanılarak yazar tarafından hesaplanmıştır.

Tablo 2'de tüm ülkelerin kapsandığ 1 Model 1'e ilişkin birim kök test sonuçlarının özeti verilmektedir. Olasılık değerlerinden de anlaşılabildiği gibi modelde yer alan her iki değişken de düzey değerinde durağandır yani birim köke sahip değildir.

Yatay kesit bağımlılı̆̆ının tespit edilmesinin ardından Model 2, Model 3 ve Model 4 için her yatay kesit biriminin zaman etkilerinden farklı ölçülerde 
etkilendiğini kabul eden, mekansal otokolerasyonu dikkate alan ve hem yatay kesit boyutunun zaman boyutundan hem de zaman boyutunun yatay kesit boyutundan daha büyük olabildiği durumlarda kullanılan Pesaran (2007) kullanılmıştır (Huseyni ve Doru, 2017, s.742). Bu test vasitasıyla paneli meydana getiren yatay kesitlerin her biri için birim kök testi icra edilebilmekte; böylelikle serilerin durağanlık derecesi panelin geneli için olduğu gibi ayrı ayrı yatay kesitler için de ayrıca ölçülebilmektedir (Pesaran, 2007, s.265-312). Bununla birlikte çalışmada tek tek ülkelerden ziyade her bir model genel olarak değerlendirilmektedir.

Tablo 3. CADF Panel Birim Kök Test Sonuçlar

\begin{tabular}{lllllllll}
\hline Model 2/ & LXM & LRX & Model 3/ & LXM & LRX & Model 4/ & LXM & LRX \\
\hline Panel & $-2.889^{*}$ & $-4.017^{*}$ & Panel & $-3.446^{*}$ & $-3.821^{*}$ & Panel & $-4.14^{*}$ & $-3.63^{*}$ \\
CIPS & & & CIPS & & & CIPS & & \\
\hline
\end{tabular}

Gecikme uzunluğu maksimum dört alınmış ve optimal gecikme uzunlukları, Schwarz kriteri dikkate alınarak belirlenmiştir. Panel istatistiği kritik değerleri, -2.57 (\%1), -2.33 (\%5) ve -2.21 (\%10) (Pesaran 2007, Table II(b), p:280); Panel istatistiği, CADF istatistiklerinin ortalamasıdır. ${ }^{*}, \% 1, * * \% 5 \mathrm{ve}^{* * *}, \% 10$ anlamlılık düzeyinde durağan olduğunu göstermektedir.

Pesaran (2007)'ye göre tablo kritik değerinin test istatistik değerlerinden mutlak anlamda küçük olması halinde seride birim kökün varlığını ifade eden temel hipotez reddedilmektedir. Tablo 3'te Model 2, Model 3 ve Model 4'e ilişkin CADF test sonuçları verilmiştir. Elde edilen test sonuçları değerlendirildiğinde tüm serilerin \%1 düzeyinde durağan olduğu başka bir ifade ile panelin genelinde birim kökün bulunmadı̆̆ı görülmektedir.

\section{Model Seçim Testleri ve Ekonometrik Bulgular}

Birim kök testlerinin ardından model seçimine ilişkin testler gerçekleştirilmiştir. Bunun için öncelikle zaman ve birim etkilerinin varlığg F testi ile kontrol edilmiştir. Test sonucunda birim ve zaman etkilerinin mevcut olmadiğ1 sonucuna ulaşılmıştır. Daha sonra ise panel veri analizinde rassal, sabit yahut ortak etki modelleri arasından en uygun modelin seçilebilmesi amacıyla Chow ve Hausman testleri yapılmıştır (Zulfikar, 2018). Hausman (1978) testi rassal etkiler ve sabit etkiler modellerinden hangisinin diğerine göre daha tutarlı sonuç verdiğini belirlemek için yapılmaktadır. Bu test, rassal etkiler modelinin hata terimleri ile modelde yer alan bağımsız değişkenler arasında bir 
korelasyonun var olmadığı varsayımına dayanmaktadır. Bu durumda sabit etkiler modelinin parametre tahmincilerinin rassal etkiler modelinin parametre tahmincilerinden farkının istatistiki olarak anlamlılı̆ının test edilmesi gerekir. Bunun için de Hausman testi kullanılmaktadır (Pazarlıŏlu ve Gürler, 2007, s.39).

\section{Tablo 4. Model Seçim Testleri}

\begin{tabular}{llll}
\hline Model 1 & İstatistik & d.f & Olasılık değeri \\
\hline Cross-section F & 3.683199 & $(45,1334)$ & 0.0000 \\
Cross-section Chi-square & 161.966503 & 45 & 0.0000 \\
Hausman Testi & 162.044512 & 3 & 0.0000 \\
\hline Model 2 & & & \\
\hline Cross-section F & 3.124361 & $(16,500)$ & 0.0000 \\
Cross-section Chi-square & 49.551632 & 16 & 0.0000 \\
Hausman Testi & 48.833539 & 3 & 0.0000 \\
\hline Model 3 & & & \\
\hline Cross-section F & 3.74553 & $(9,268)$ & 0.0002 \\
Cross-section Chi-square & 33.292666 & 9 & 0.0001 \\
Hausman Testi & 33.297496 & 3 & 0.0000 \\
\hline Model 4 & & & \\
\hline Cross-section F & 2.708307 & $(18,560)$ & 0.0002 \\
Cross-section Chi-square & 48.579598 & 18 & 0.0001 \\
Hausman Testi & 47.264912 & 3 & 0.0000 \\
\hline
\end{tabular}

Not: Tablodaki değerler Eviews 9 programı kullanılarak yazar tarafından hesaplanmıştır.

Tablo 4'te de görüldüğü üzere çalışmada analiz edilen bütün modeller için Chow testinin sonucunda sabit etkiler ve ortak etki modelleri arasından sabit etkiler modelinin; Hausman test sonuçlarına göre ise olasılık değeri \%5 anlamlılık düzeyinden yüksek olması nedeniyle en uygun model olarak sabit etkiler modelinin tercih edilmesi gerektiği sonucuna ulaşılmıştır. Sabit etkiler modeli sabit terimin birimlere göre farklılık gösterdiği doğrusal regresyon modelidir (Verbeek, 2004, s.345). Sabit etkiler modelinde her bir birim için farklı bir sabit terim katsayısı bulunmaktadır. Sabit terim katsayıları birimden birime farklı değerler almaktadır. Bu katsayılar aynı zamanda modele dâhil edilmeyen fakat zaman içinde sabit kalmış değişkenlerin etkisini içermektedir. Bağımsız değişkenlerin katsayıları ise sabit olarak kalmaktadır (Stock ve Watson, 2006, s.356).

Model tercih testlerinin sonuçlarına bağlı olarak aşağıda verilen regresyon modelinde dış ticaret dengesinden bütçe dengesine doğru herhangi bir ilişkinin var olup olmadığı analiz edilmektedir. Modelin gecikme uzunlukları Akaike, Schwarz ve Hannan-Quinn değerleri çerçevesinde belirlenmiştir. 
$(\mathrm{LXM}) t=\beta 0+\beta 1(\mathrm{LRX}) t+\beta 2(\mathrm{LXM}) t-1+\beta 2(\mathrm{LXM}) t-2+\varepsilon t$

Oluşturulan sabit etkiler modeline ilişkin regresyon sonuçları aşağıdaki tabloda gösterildiği gibidir.

Tablo 5. Model Tahmin Sonuçlarn

\begin{tabular}{lllllllll}
\hline \multirow{2}{*}{$\begin{array}{l}\text { Değiş- } \\
\text { ken }\end{array}$} & Model 1 & \multicolumn{3}{c}{ Model 2 } & \multicolumn{3}{c}{ Model 3 } & Model 4 \\
\cline { 2 - 8 } & Katsayı & $\begin{array}{l}\text { Olasılık } \\
\text { değeri }\end{array}$ & Katsayı & $\begin{array}{c}\text { Olasılık } \\
\text { değeri }\end{array}$ & Katsay1 & $\begin{array}{c}\text { Olasilık } \\
\text { değeri }\end{array}$ & Katsayı & $\begin{array}{l}\text { Olasılık } \\
\text { değeri }\end{array}$ \\
\hline LXM & 1 & 1 & & 1 & & 1 & \\
LRX & 0.01067 & 0.6677 & -0.0318 & 0.3719 & 0.01712 & 0.7638 & 0.04061 & 0.2822 \\
LXM(-1) & 0.46673 & 0.0000 & 0.57449 & 0.0000 & 0.32166 & 0.0000 & 0.59519 & 0.0000 \\
LXM(-2) & 0.15123 & 0.0000 & 0.15571 & 0.0005 & 0.09631 & 0.1196 & 0.12479 & 0.0029 \\
c & -0.0007 & 0.8780 & -0.0469 & 0.0000 & 0.13105 & 0.0000 & 0.01037 & 0.1205 \\
\hline$R^{2}$ & 0.76092 & & 0.86351 & & 0.46354 & & 0.80934 & \\
\hline F-prob & 0.0000 & & 0.0000 & & 0.0000 & & 0.0000 & \\
\hline DW-ist. & 2.04088 & & 2.0447 & & 2.0456 & & 2.0075 & \\
\hline
\end{tabular}

Not: Tablodaki değerler Eviews 9 programı kullanılarak yazar tarafından hesaplanmıştır.

Modellerde otokorelasyonun varlığını test etmek amacıyla Wooldridge (2002) takip edilerek; elde edilen hata terimleri kendi bir gecikmeli değerleri ile regresyona sokulmuş ve uygulanan Wald testi neticesinde gecikmeli değerin katsayısının -0.5'e eşit olup olmadığı test edilmiştir. Wald testi neticesinde her bir model için elde edilen olasılık değerleri (Model 1 için 0.068275, Model 2 için 0.051674 , Model 3 için 0.064053 ve Model 4 için 0.054725 ) \% $\%$ 'ten büyük olup modelde otokorelasyon sorunun olmadığ ifade edilebilir.

Modelde değişen varyansın varlığını test etmek için White Heteroskedastisite Testi uygulanmıştır. Test sonucunda tüm modeller için elde edilen olasılık değeri $\% 5$ 'ten küçük olup değişen varyansın olmadığını ifade eden sıfır hipotezi reddedilerek, modelde değişen varyansın olduğu bulgusuna ulaşılmıştır. Değişen varyansın varlığı, parametre tahminlerini etkilemeyecek ve elde edilen katsayılar sapmasız olacaktır fakat tahmin edilen parametrelerin varyansı sapmalı hale gelecek ve $\mathrm{t}$ - değerleri güvenilirliğini kaybedecektir (Herrera, 2012, s.1091). Değişen varyansın varllğı durumunda ortaya çıkan bu sakıncayı giderebilmek ve daha etkin tahmincilere ulaşabilmek amacıyla robust regresyon tahminleri yapılmıştır. 
Tablo 6. Robust Regresyona İlişkin Tahmin Sonuçları

\begin{tabular}{|c|c|c|c|c|c|c|c|c|}
\hline \multirow{2}{*}{$\begin{array}{l}\text { Değiş- } \\
\text { ken }\end{array}$} & \multicolumn{2}{|l|}{ Model-1 } & \multicolumn{2}{|l|}{ Model-2 } & \multicolumn{2}{|l|}{ Model-3 } & \multicolumn{2}{|l|}{ Model-4 } \\
\hline & Katsay1 & $\begin{array}{l}\text { Olasillk } \\
\text { değeri }\end{array}$ & Katsayı & $\begin{array}{l}\text { Olasılık } \\
\text { değeri }\end{array}$ & Katsayı & $\begin{array}{l}\text { Olasillk } \\
\text { değeri }\end{array}$ & Katsayı & $\begin{array}{l}\text { Olasilık } \\
\text { değeri }\end{array}$ \\
\hline LXM & 1 & & 1 & & 1 & & 1 & \\
\hline LRX & 0.01018 & 0.6091 & -0.0095 & 0.6656 & 0.00819 & 0.7800 & 0.025268 & 0.5611 \\
\hline LXM(-1) & 0.635195 & 0.0000 & 0.70432 & 0.0000 & 0.476046 & 0.0000 & 0.772397 & 0.0000 \\
\hline $\operatorname{LXM}(-2)$ & 0.235432 & 0.0000 & 0.21704 & 0.0003 & 0.22172 & 0.0000 & 0.104199 & 0.0623 \\
\hline $\mathrm{C}$ & 0.00028 & 0.9503 & -0.0122 & 0.0280 & 0.06650 & 0.0029 & 0.002632 & 0.7203 \\
\hline $\mathrm{R}^{2}$ & 0.708572 & & 0.8124 & & 0.39567 & & 0.750753 & \\
\hline F-prob & 0.0000 & & 0.0000 & & 0.0000 & & 0.0000 & \\
\hline DW-ist. & 2.04718 & & 2.0232 & & 2.01862 & & 2.007833 & \\
\hline
\end{tabular}

Not: Tablodaki değerler Gretl programı kullanılarak yazar tarafından hesaplanmıştır.

Tahmin sonuçları değerlendirildiğinde modellerin genel olarak anlamlılık düzeylerinin ve bağımsız değişkenlerin bağımlı değişkeni açılama gücünün yüksek olduğu, $\mathrm{R}^{2}$ ve $\mathrm{F}$ değerlerinden anlaşılabilmektedir. Bununla birlikte bütün modellerde de kamu dengesini yansitan LRX değişkeni, istatistiki olarak anlamsızdır. Modellere bağımsız değişken olarak ilave edilen bağımlı değişkenin gecikmeli değerleri ise istatistiki olarak anlamlı oldukları gibi her dört modelde de katsayıları pozitiftir. Bu anlamda özellikle dış denge yahut dengesizlik sürecinin birikimli ve kronik olduğu ifade edilebilir. Önceki senelerden gelen etkiler, yakın döneme doğru sönümlenmektedir. Başka bir ifade ile ilgili ülke grubunda genel olarak önceki senelerde meydana gelen dış dengesizlikler kısa dönemde ciddi ölçüde, uzun vadede ise giderek zayıflayarak cari dönemdeki dengesizlikleri tetiklemektedir.

Çalışma kapsamında son olarak mevcut analizleri destekleyici olması açısından Granger Nedensellik Testi yapılmıştır. Böylece ihracatın ithalata oranını ifade eden ve dış dengeye karşılık gelen LXM ile kamu gelirlerinin kamu giderlerine oranını temsil eden ve kamu dengesine karşılık gelen LRX arasinda herhangi bir nedenselliğin var olup olmadığ 1 ve eğer varsa nedenselliğin yönü hakkında bilgi sahibi olunması amaçlanmıştır. Bunun için Dumitrescu-Hurlin Nedensellik Testi uygulanmıştır. Dumitrescu-Hurlin Nedensellik Testi, yatay kesit bağımlılığını ve heterojenliği dikkate aldığı gibi değiş̧kenler arasında eşbütünleşik ilişkinin varlık yahut yokluk durumlarında da etkin sonuçlar verebilmektedir (Dumitrescu ve Hurlin, 2012, s.1450). Nedensellik testine ilişkin sonuçlar aşağıda yer alan tabloda gösterilmektedir. 
Tablo 7. Dumitrescu - Hurlin Nedensellik Test Sonuçlan

\begin{tabular}{|c|c|c|c|c|}
\hline & & W-Stat & Zbar-Stat & Olasılık Değeri \\
\hline \multirow{2}{*}{ Model 1} & Ho: LRX, LXM'in Granger nedeni değildir. & 2.23598 & 0.18392 & 0.8541 \\
\hline & Ho: LXM, LRX'in Granger nedeni değildir. & 5.85044 & 10.5385 & 0.0000 \\
\hline \multirow{2}{*}{ Model 2} & Ho: LRX, LXM'in Granger nedeni değildir. & 1.63723 & -0.92870 & 0.3530 \\
\hline & Ho: LXM, LRX'in Granger nedeni değildir. & 4.55770 & 4.17206 & 0.0000 \\
\hline \multirow{2}{*}{ Model 3} & Ho: LRX, LXM'in Granger nedeni değildir. & 2.48027 & 0.39396 & 0.6936 \\
\hline & Ho: LXM, LRX'in Granger nedeni değildir. & 4.54488 & 3.12303 & 0.0018 \\
\hline \multirow{2}{*}{ Model 4} & Ho: LRX, LXM'in Granger nedeni değildir. & 2.64313 & 0.87594 & 0.3811 \\
\hline & Ho: LXM, LRX'in Granger nedeni değildir. & 7.69423 & 10.2037 & 0.0000 \\
\hline
\end{tabular}

Not: Tablodaki değerler Eviews 9 programı kullanılarak yazar tarafından hesaplanmıştır.

Nedensellik test sonuçlarından elde edilen bulgulara göre her dört model için de LRX, LXM'nin yani kamu dengesi dış dengenin nedeni değil iken; LXM, LRX'nin yani diş denge kamu dengesinin nedenidir. Bu durumda \%5 anlamlılık düzeyinde LXM değişkeninden LRX değişkenine doğru bir panel nedensellik ilişkisi söz konusudur. Çalışmanın iktisat literatürüne olan katkısı Tablo 6 ve Tablo 7 bağlamında bir bütün olarak değerlendirildiğinde 1881-1913 dönemi ve farklı ülke grupları için oluşturulan modeller bağlamında İkiz Açık Hipotezi geçerli değildir. Nedensellik ilişkisi hipotezde ifade edildiği üzere kamu dengesinden dış dengeye doğru değil, dış dengeden kamu dengesine doğrudur. Bu bağlamda Ricardian Denklik Hipotezi'nin geçerli olduğu ifade edilebilir. Fakat bunun için dönemin koşullarının iyi değerlendirilmesi gerekmektedir. Nitekim bu dönemde çevre ve yarı-çevre ülkelerin büyük kısmı önemli bir borç yükü içerisindedir. Bu nedenle Ricardian Eşdeğerlilik Kuramı́nın ileri sürdüğü gibi kamu açıkları ile dış yahut cari açık arasındaki tek yönlü ilişkiyi ortadan kaldırabilecek şekilde planlanan tasarruf artışının dış borçlanma gerekliliğini ortadan kaldırması durumunun geçerliliği şüphelidir.

\section{Sonuç}

Bu çalışmada İkiz Açık Hipotezi, tarihsel verilerle ve farklı ülke grupları için değerlendirilmiştir. Ülke gruplandırmaları merkez-çevre ilişkileri bağlamında yapılmıştır. Teorik anlamda literatürde oldukça çok sayıda çalışma bulunmasına rağmen hipotezin 1980'li yıllarda ABD'de yaşanan ekonomik durumdan esinlenmesi nedeniyle tarihsel verileri kullanan çalışmalar oldukça sınırlıdır. Çalışmanın iktisat literatürüne olan katkısı da bu noktada kendisini göstermektedir. Nitekim Keynes (1999), İktisat Tarihi'ni İktisat Teorisi'nin bugünkü bulgularının tarihsel açıdan doğru olup olmadığını test 
eden bir faaliyet olarak tanımlamaktadır. Dolayısıyla bu çalışmada söz konusu İkiz Açık Hipotezi'nin geçmiş dönemlerde ve farklı uluslararası ekonomik mekanizmalar üzerinden geçerlilik kazanmış olabileceği düşüncesinden hareket edilmiştir.

Çalışmanın bulguları çerçevesinde değerlendirildiğinde ekonometrik olarak analiz edilen hiçbir modelde de bağımsız değişken olan kamu dengesi değişkeninin katsayısı, istatistiki olarak anlamlı bulunmamış ve bu nedenle de yorumlanamamıştır. Bununla beraber bağımlı değişkenin yani dış dengenin gecikmeli değerleri, hem pozitif değer almış hem de istatistiki olarak anlamlı bulunmuştur. Bu bakımdan her dört modelde de dış dengede meydana gelen değişmelerin birikimli bir süreç halinde ve sönümlenerek cari döneme intikal ettiği ifade edilebilir. Son olarak yapılan nedensellik testinde ise yine İkiz Açık Hipotezi'nin öne sürdüğünün aksine nedenselliğin yönü kamu dengesinden dış dengeye doğru değil, bilakis dış dengeden kamu dengesine doğru gerçekleşmiştir.

Sonuç olarak bu çalışma kapsamında I. Dünya Savaşı öncesi iktisadi ve politik istikrarsızlığın egemen olduğu süreçte merkez, yarı çevre ve çevre olmak üzere tüm ülke grupları için de İkiz Açık Hipotezi'ne ilişkin geleneksel açıklama geçerli değildir. Bu bağlamda Ricardian Eşdeğerlilik Kuramı́nın geçerli olduğu ifade edilebilse de bunun için ilave spesifik çalışmalar yapmak gereklidir. Dolayısıyla bu çalışmanın bir katkısı da çalışmada elde edilen sonuçlarla bağlantılı yeni çalışmalar için merak ve motivasyon sağlayacak olmasidir. 


\title{
EXTENDED ABSTRACT
}

\section{İkiz Açık Hipotezinin Tarihsel Geçerliliğinin Panel Veri Yaklaşımı ile Analizi}

\author{
Mehmet Çetin \\ Dokuz Eylul University
}

The negative impact of the budget deficit on the external balance due to the increase in public expenditures is called the twin deficit in the literature. The differences in the Classical, Keynesian and Monetarist approaches regarding the Twin Deficit Hypothesis arise from the idea that different macroeconomic instruments will have a regulatory effect on the balance of payments. In this sense, the Monetarist approach emphasizes the money supply, while the Keynesian approach emphasizes the contractionary fiscal policy and the Classical School emphasizes exchange rates.

This study analyzes the validity of the Twin Deficit Hypothesis for the 1881-1913 period and for 46 countries which are classified as the center countries and periphery countries following Pamuk(2005) using the Panel Data Analysis. The main purpose of the center country is to manage and direct the production patterns in the periphery in line with its own interests. This process includes both a potential foreign trade deficit and a potential budget deficit for the periphery. Moreover, the period of the study is also the period in which the monopolistic capitalism evolved into imperialism. The fact that the Twin Deficit Hypothesis is a relatively up-to-date theory, has neglected the questioning of the historical validity of the theory. In this sense, there are very few studies in the literature. This situation constitutes both the importance and the starting point of this study.

These 46 countries are categorized into three different countries according to the classification of Pamuk(2005) as center, periphery and unofficial empires. Four different models were developped in the study including different countries. The first model includes the whole countries, the second model includes the center countries, the third model includes the nonformal empires (semi-periphery) and the fourth model includes the periperhy countries. The data used in the study is obtained from B. R. Mitchell (1982 ve 1998), The Statesman's Year-Book, Güran (2003) and Pamuk (1995). The budget balance 
(LRX) which is the ratio of budget revenues to government expenditures and the foreign trade balance (LXM) which is the ratio of exports to imports are defined logarithmically.

Since the 19th century was defined as the first era of globalization, and although we can accept that the transportation and communication facilities were more limited compared to today, international economic relations have shown a great improvement when the progress of telegraph, telephone, ocean and rail transportation is taken into consideration. The development of mutual economic relation increased the mutual interaction between the countries. Accordingly, there are mutual interaction between these units forming the cross section in the econometric analysis phase. In the first generation panel unit root tests, it is assumed that the cross sections forming the series are independent from each other and that all units are equally affected by a shock that may ocur in any of the units that forms the series. In the second generation panel unit root tests, it is assumed that a shock in an of the units that forms the panel will have different effects on all units. Since the unit size (46 countries) is larger than the time dimension (33 years) for Model 1, Pesaran (2004) cross-section dependence test was adopted and LM test developped by Breusch and Pagan (1980) was used for the other model since the time dimension is bigger than the unit size. According to the results obtained from the cross-section dependency test, the probability value obtained in the first model is greater than $\% 5$ and there is no cross section dependency for the first model. However there is a cross- section dependency for the other models. Therefore, there is a correlation between units. In this framework, in the next step, first generation unit root tests were applied for the first model and second generation tests were applied for the other models. When the test results are evaluted it can be seen that there is no unit root in the panel for both models.

Following the unit root tests, model selection tests were carried out. For this, the existence of time and unit effects were checked with the F test. As a result of the test it was concluded that there were not unit and time effects. Afterwards, Chow and Hausman tests were conducted in order to select the most suitable model among random, fixed and common effect models in panel data analysis. According to the results of the model selection tests the fixed effects model was preferred as the most appropriate model. The lag 
lengths of the model were determined within the framework of Akaike, Schwarz and Hannan-Quinn values. The model is shown below.

$$
(\mathrm{LXM}) t=\beta 0+\beta 1(\mathrm{LRX}) t+\beta 2(\mathrm{LXM}) t-1+\beta 2(\mathrm{LXM}) t-2+\varepsilon t
$$

In order to test the existence of autocorrelation and heteroscedasticity Woolridge(2002) and White tests were adopted in the models. As a result of the tests, it can be stated that there is no autocorrelation problem but there is heteroscedasticity in the models. Robust regression estimations were done in order to overcome this drawback that occurs in the presence of heteroscedasticity and to obtain more effective estimators.

When the estimation results are evaluted, it can be understood from the $\mathrm{R} 2$ and $\mathrm{F}$ values that the general significance levels of the models and the power of the independent variable to explain the dependent variable are high. However, the LRX variable, which reflects the budget balance in all models, is statistically insignificant. The lagged values of the dependent variable added to the models as an independent variable are statistically significant, as well as their coefficients are positive in all four models. In this sense it can be stated that the process of imbalance is cumulative and chronic. In the scope of the study, Granger Causality Test was conducted to support the existing analyzes. Thus, it is aimed to have information about whether there is any causality between LXM and LRX. For this, Dumitrescu-Hurlin Causality Test was applied. According to the findings; LRX is not the cause of LXM since LXM is the cause of LRX. In this case there is a panel causality relationship from LXM to LRX at 5\% significance level. When the contribution of the study to the literature it can be stated that the Twin Deficit Hypothesis is not valid for the period of 1881-1913 for different country groups. As mentioned above the causality relation is not from budget balance to external balance but from external balance to budget balance. As a result the traditional explanation regarding the Twin Deficit Hypothesis is not valid for all country groups, including center, semi-periphery and periphery in the period when economic and political instability prevailed befor the WWI. In this context although it can be stated that the Ricardian Equivalence Theory is valid, additional specific studies are required for this. Therefore, one of the contributions of this study is that it will provide curiosity and motivation for new studies related to the results obtained in the study. 


\section{Kaynakça / References}

Abell, J. D. (1990). Twin deficit during the 1980s: An emprical investigation. Journal of Macroeconomics, 12(1), 81-96.https://doi.org/10.1016/0164-0704(90)90057-H

Alkswani, M. A. (2000). The twin deficit phenomenon in petroleum economy: Evidence from Saudi Arabia. Seventh Annual Conference, Economic Research Forum, Amman. 12 Şubat 2020 tarihinde http://www.mafhoum.com/press2/79E15.pdf adresinden erişildi.

Anoruo, E. ve Ramchander, S. (1998). Current account and fiscal deficits: Evidence from Developing Economies of Asia. Journal and Asian Economics, 9(3), 487-501. https://doi.org/10.1016/S1049-0078(99)80099-2

Ball, L. ve Gregory N. M. (1995). What do budget deficit do?. NBER Working Paper Series Working Paper No. 5263, 1-36. DOI: 10.3386/w5263

Barro, R. J. (1989). The Ricardian approach to budget deficit. Journal of Economic Perspectives 3(2), 37-54. DOI: $10.3386 /$ w2685

Beetsma, R, Giuliodori, M. ve Klaassen, F. (2008). The effects of public spending shocks on trade balances and budget deficits in the European Union. Journal of the European Economic Association, 6(2), 414-423. https://doi.org/10.1162//EEA.2008.6.2-3.414

Bernheim, D. B. (1988). Budget deficits and the balance of trade. Tax Policy and Economy 2, 1-32. 10 Ocak 2020 tarihinde https://www.nber.org/chapters/c10935.pdf adresinden erişildi.

Bilgili, E., ve Bilgili, F. (1998). Bütçe açıklarının cari işlemler dengesi üzerindeki etkileri: Teori ve uygulama. İktisat İsletme-Finans Dergisi, 146, 4-16.

Bilman, M. E. (2019). Osmanlı İmparatorluğu'nda ikiz açk hipotezinin araştırlmast: nedensellik analizlerinden kantlar. Ü̧̧üncü İktisat Tarihi Kongresi Bildirileri-3. 25-27 Nisan 2019 İzmir, 279-289. 11 Ocak 2020 tarihinde http://iktisattarihi2019.idu.edu.tr/wp-content/uploads/3.Iktisat Tarihi Kongresi.pdf adresinden erişildi.

Biswas, B., Gopal T. veSaunders, P. (1992). Further analysis of the twin deficits. Contemporary Economic Policy, 10(1), 104-108. https://doi.org/10.1111/j.14657287.1992.tb00217.x

Breusch, T. S. ve Pagan, A. R. (1980). The lagrange multiplier test and its appliations to model specification in econometrics. The Review of Economic Studies, 47(1), 239253. https://doi.org/10.2307/2297111

Çetin, M. ve Kök, R. (2015). Osmanlı dış borçlanmasının Hobson-Lenin Tezi Bağlamında Değerlendirilmesi. Akademik Bakış Dergisi, 51, 203-220. 
Dewald, G. W. ve Ulan, M. (1990). The twin deficit 1lusion. Cato Journal, 9(3), 689-707. 22

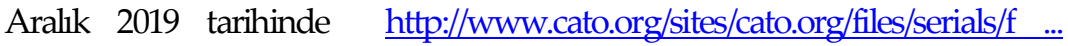
1/1990/1/cj9n3-9.pdf adresinden erişildi.

Dibooğlu, S. (1994). Accounting for US current account deficits: An empirical investigation. Applied Economics, 29, 787-793. 22 Aralık 2019 tarihinde http://www.tandfonline.com/doi/abs/10.1080/000368497326705 adresinden erişildi.

Dumitrescu, E. I. ve Hurlin, C. (2012). Testing for granger non-causality in heterogeneous panels. Economic Modelling, 29(4), 1450-1460. https://doi.org/10.1016/j.econmod.2012.02.014

Eroğlu, A. S. (1998). Bütçeaçı̆̆ı-cari işlemler açı̆̆ı ilişkisi: Türkiye üzerine bir deneme. Y1llıkProgramlar ve Konjonktür Değerlendirme Genel Müdürlüğü. Yayın No: 2489. Ankara: Devlet Planlama Teşkilatı 26 Aralık 2019 tarihinde http://www.sbb.gov.tr/wp-content/uploads/2018/11/AhmetSabriEROGLU.pdf adresinden erişildi.

Evans, P. (1988). Are Consumers Ricardian? Evidence for the United States. Journal of Political Economy, 96 (5), 983-1004.

Evans, P. ve Hasan, I. (1994). Are consumers Ricardian? Evidence for Canada. Quarterly Review of Economics and Finance, 34(1), 25-40. https://doi.org/10.1016/10629769(94)90051-5

Feldstein, M. (1986). Budge deficit, tax rules, and real interest rates. NBER Working Paper Series No. 1970, 5-18. DOI: 10.3386/w1970

Granger, C. W. ve Newbold, P. (1974). Spurious regression in econometrics. Journal of Econometrics, 2, 111-120. https://doi.org/10.1016/0304-4076(74)90034-7

Günaydın, İ. (2004). Bütçe ve ticaret açıkları arasındaki ilişki: Türkiye uygulaması. Ekonomik Yaklaşım Dergisi, 15, 143-159. DOI:10.5455/ey.10504

Güran, T. (2003). Osmanlı mali istatistikleri bütçeler, 1841-1918. Ankara: Türkiye Cumhuriyeti Devlet İstatistik Enstitüsü.

Güran, T. (2017). İktisat tarihi. İstanbul: Der Yayınları.

Herrera, E. G. (2013). Comparing alternative methods to estimate gravity models of bilateral trade. Empirical Economics, 44(3), 1087-1111.https://oi.org/10.1007/s00181$\underline{012-0576-2}$

Hüseyni, İ. ve Doru, Ö. (2017). Türkiye ve gelişmiş ülkelerde turizm gelirleri ve gsyh arasındaki ilişkinin yeni nesil panel veri testleri ile incelenmesi. Uluslararası Sosyal Araştırmalar Dergisi, 10(53), 739-746. DOI: 10.17719/jisr.20175334162

Kasa, K. (1994). Finite horizons and the twin deficits. Federal Reserve Bank of San Francisco Economic Review, 3, 19-28. 
Kaufmann, S., Scharler, J. ve Winckler, G.(1999). The Austrian current account deficit: Driven by Twin Deficits or by Intertemporal Expenditure Allocation?. Emprical Economics, 27(3), 529-542. https://doi.org/10.1007/s001810100094

Keltie, S. J. (ed) (1891). The Stateman's year-book, statistical and historical annual of the states of the world for the year 1891. Mac London: Macmillan and Co.

Kenen, P. B. (2000). The International Economy. 4th Edition. United Kingdom: Cambridge University Press.

Keynes, J. N. (1999). The scope and method of political economy. Batoche Books.

Kılavuz, E. ve Dumrul, Y. (2012). İkiz açıklar hipotezinin geçerliliği: Teori ve uygulama. Atatürk Üniversitesi İktisadi ve İdari Bilimler Dergisi, 26(3-4), 239-258.

Kim, S. ve Roubini, N. (2008). Twin deficit or twin divergence? Fiscal policy, current account, and real exchange rate in the US. Journal of International Economics, 74 (2,:362383.https://doi.org/10.1016/j.jinteco.2007.05.012

Krugman, P. R., Obstfeld, M. ve Melitz, M. J. (2014). International Economics Theory and Policy. 10th Edition, USA: Pearson.

Kulkarni, K. G. ve Erickson, E. L. (2001). Twin deficit revisited: Evidence from India, Pakistan and Mexico, Journal of Applied Business Research, 17(2), 87-100. Doi: 10.19030/jabr.v17i2.2076

Lau, E. ve Baharumshah, A. Z. (2006). Twin Deficits Hypothesis in SEACEN Countries: A panel data analysis of relationships between public budget and current account deficits. Applied Econometrics and International Development, 6-2, 213-226. 1 Şubat $2020 \quad$ tarihinde https://pdfs.semanticscholar.org/e838/c1dcc00d6078a5fbf96a11fdfd8acd23c8f0.pdf adresinden erişildi.

Mammadov, F. (2008). Bütçe açıklarının finansmanı ve makroekonomik etkileri: Azerbaycan örneği: 1992-2006. Yayınlanmamış Yüksek Lisans Tezi, İstanbul Üniversitesi Sosyal Bilimler Enstitüsü, İstanbul.

Martin, F. (1882). The Stateman's Year-Book, statistical and historical annual of the civilised world for the year 1882. London: Macmillan and Co.

Mitchell, B. R. (1982). International historical statistics: Africa and Asia. 1st Edition. London: Macmillan Reference Ltd.

Mitchell, B. R. (2003). International historical statistics. Africa, Asia E Oceania. Third Edition. London: Macmillan Reference Ltd.

Mitchell, B. R. (2003). International historical statistics: Europe. Fourth Edition. London: Macmillan Reference Ltd.

Obstfeld, M. ve Rogoff, K. (1996). Foundations of international macroeconomics. Cambridge: The MIT Press.

Pamuk, Ş. (2005). Osmanlı - Türkiye iktisadi tarihi: 1500-1914. İstanbul: İetişim Yayınları. 
Parkin, M. (2000). Economics. Fifth Edition. USA: Addison-Wesley Publishing Company. Pazarlioğlu, M. V. ve Gürler, Ö. K. (2007). Telekomünikasyon yatırımları ve ekonomik büyüme: Panel veri yaklaşımı. Finans Politik E Ekonomik Yorumlar Dergisi, 44(508), 35-43.

Pesaran, M. H. (2004). General diagnostic tests for cross section dependence in panels. Cambridge Working Papers in Economics CWPE 0435, 1-39. 10 Ocak tarihinde http://ftp.iza.org/dp1240.pdf adresinden erişildi.

Pesaran, M. H. (2007). A simple panel unit root test in the presence of cross-section dependence. Journal of Applied Econometrics, 22, 265-312. https://doi.org/10.1002/jae.951

Phillips, P. C., ve Donggyu S. (2003). Dynamic panel estimation and homogeneity testing under cross section dependence. The Economic Journal, 6(1), 217-259. https://doi.org/10.1111/1368-423X.00108

Piersanti, G. (2000). Current account dynamics and expected future budget deficits: Some international evidence. Journal of International Money and Finance, 19, 325-352. https://doi.org/10.1016/S0261-5606(00)00004-8

Stock, J. H. ve Watson, M. W. (2006). Introduction to econometrics, 2nd Edition. Boston: Pearson.

Tanzi, V. (1982). Fiscal disequilibrum in developing countries. Word Development, 10(12), 1069-1082. https://doi.org/10.1016/0305-750X(82)90019-5

Tatoğlu, F. Y. (2017). Panel zaman serileri analizi. İstanbul: Beta Yayınevi.

Turan, T. ve Karakaş, M. (2017). İkiz açklar hipotezine doğrusal olmayan sınır testi yaklaşımı. Maliye Dergisi, 173, 211-227.

Utkulu, U. (2003). Türkiye'de bütçe açıkları ve dış ticaret açıları gerçekten ikiz mi? kontegrasyon ve nedensellik bulguları. Dokuz Eylül Üniversitesi İktisadi ve İdari Bilimler Fakültesi Dergisi 18(18), 45-61.

Vamvoukas, G. A. (1999). The twin deficits phenomenon: Evidence from Greece, Applied Economics, 31, 1093-1100. https://doi.org/10.1080/000368499323571

Verbeek, M. (2004). A guide to modern econometrics. 2nd Edition. Chichester: John Wiley \& Sons, Ltd.

Vyshnyak, O. (2000). Twin deficit hypothesis: The case of Ukraine. 2 Mart 2020 tarihinde https://kse.ua/wp-content/uploads/2019/02/Vyshnyak-1.pdf adresinden erişildi

Wooldridge, J. M. (2002). Econometric analysis of cross section and panel data. The London: MIT Press.

Yalçınkaya, Ö. ve Kaya, V. (2017). Doğal işsizlik oranı mı yoksa; işsizlik histerisi mi?: OECD Ülkeleri için yeni nesil panel birim kök testlerinden kanıtlar (1980-2015). Selçuk Üniversitesi İktisadi ve İdari Bilimler Fakültesi Sosyal Ekonomik Araştırmalar Dergisi, 17(33), 1-18. https://doi.org/10.30976/susead.327631 
Yıldırım, K., Mercan, M. ve Kostakoğlu, S. F. (2013). Satın alma gücü paritesinin geçerliliğinin test edilmesi: Zaman serisi ve panel veri analizi. Eskişehir Osmangazi Üniversitesi İktisadi ve İdari Bilimler Fakültesi Dergisi, 8(3), 75-95.

Zulfikar, R. (2019). Estimation model and selection method of panel data regression: An overview of common effect, fixed effect, and random effect model. 10 Ocak 2020 tarihinde https://osf.io/9qe2b/download/?format=pdf adresinden erişildi.

\section{Kaynakça Bilgisi / Citation Information}

Çetin, M. (2020). İkiz açık hipotezinin tarihsel geçerliliğinin panel veri yaklaşımı ile analizi. OPUS-Uluslararası Toplum Araştırmaları Dergisi, 16(32), 4939-4965. DOI: 10.26466/opus.698699 